\title{
Sciendo
}

\section{Strategic SCM's Mediating Effect on the Sustainable Operations: Multinational Perspective}

\author{
Sebastian KOT ${ }^{1}$, Adnan ul HAQUE ${ }^{2}$ and Eugene KOZLOVSKI ${ }^{3}$
}

\begin{abstract}
${ }^{1}$ The Management Faculty, Czestochowa University of Technology, Armii Krajowej 19B, 42-201 Częstochowa, Poland, and North-West University, Department of Entrepreneurship, Faculty of Economic Sciences and IT, South Africa, sebacat@zim.pcz.pl

${ }^{2}$ Faculty of Business and Management, University of Wales Trinity Saint David - London Campus, Winchester House, 11 Cranmer Road, SW9 6EJ, London, United Kingdom, adnan@sribp.com

${ }^{3}$ Faculty of Business and Management, University of Wales Trinity Saint David - London Campus, Winchester House, 11 Cranmer Road, SW9 6EJ, London, United Kingdom, and Dublin Centre for European Strategy, 75 Merrion Square, Dublin, Ireland, eugene.kozlovski@uwtsd.ac.uk
\end{abstract}

Background and Purpose: The comparative cross-sectional study examines the strategic supply chain management's mediating effect on the sustainable operations through environmental and social sustainability within the businesses operating in Canada, Iran and Turkey to attain global perspective.

Methodology: Over 200 small businesses in each country are included through combining purposive sampling, referrals, networking, and connections. For quantitative data analysis, the Smart partial least square structural equation modeling (SmartPLS-SEM) is employed.

Results: Results showed that there is statistically significant positive mediating role of strategic supply chain on the sustainable operations (environmental and social sustainable) performances in all three selected economies. Findings further confirmed that within the multinational perspective, the SCM factors have higher significant positive impact within Canada in contrast to Iran and Turkey.

Conclusion: This study offers a new theoretical contribution by examining the mediating role of strategic supply chain from multinational perspective to enhance existing body of knowledge. Furthermore, it offers a practical contribution by providing the strategic research framework to facilitate managers in improving the small businesses' performance in sustaining operations.

Keywords: Environmental sustainability, multinational perspective, social sustainability, sustainable operations, strategic supply chain management

\section{Introduction}

At national and international level, the economic growth improves to a larger extent through the operations of Small businesses (OECD, 2009). For the survival and thriving within the complex business environment, it is essential for the SMEs operating in different economies to develop and execute appropriate strategies (Kljucnikov, Belas, Kozubikova and Pasekova, 2016; Kozubikova, Homolka and Kristalas, 2017). Therefore, the conceptual application of the supply chain management within the SMEs related to functioning strategies forms as most important aspect

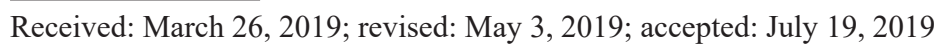


because of the operations of supply chain closely associated with the set of activities, starting from extraction of raw material by means of transformation and flow of products till reaching the end-consumers (Kovács and Kot, 2016). Within the procedure of supply chain activities, the flow of information is also very important. Liberko, Bednarová, Hajduová and Chovancová (2015) stated that the supply chain perspective is more vital focus in the present era because of intense competition. To larger extent in modern era, there has been growth in the technological advance- ment for accessing information, on time deliver and providing good quality products at affordable prices to meet expectations of the consumers (Kovács and Kot, 2016; Liberko et al. 2015). Conversely, it is vital that businesses take proper measures and actions to ensure there is preferably no or limited negative impact on the environment and societies because these firms do not operate in vacuum. Thus, it is pivotal for the small businesses to ensure that the functionality of supply chain management is carried out in rightly strategic manner.

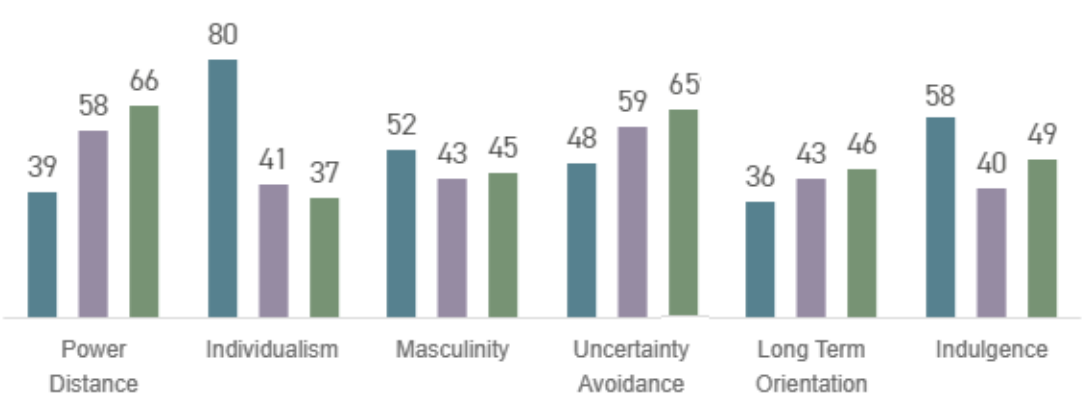

Figure 1: Hofstede's Cultural Dimension Comparison (Source: Hofstede-insight.com)

Kovács and Kot (2016) found that the operations and process of supply chain management remain similar to larger extent in all types of economies. In order to have multinational perspective, three distinctive economies are considered that shares similar features and trends within the SMEs sector. Moreover, Hofstede's cultural dimensions are considered as another criteria for selection of the distinctive countries. Considering Hofstede's cultural dimension, the criteria was set to ensure $50 \%$ of the dimensions to be similar in properties. In this regard, masculinity is one dimension that are closed to similar as of now Canada (52), Iran (43) and Turkey (45) masculinity. Hence, all three have almost over 40 scores in masculinity, which means there is higher masculine culture. Another dimension is "long-term orientation" having fractional variation among Canada (36), Iran (43) and Turkey (46). Additionally, "uncertainty avoidance" are also similar to large extent Canada (48), Iran (59) and Turkey (65) while indulgence is Canada (58), Iran (40) and Turkey (49). Thus, to some extent, four dimensions have almost similar types of set of properties and therefore, these are considered cases for this study.
Another criterion for the selection of these cases is based on the Human Development Index (HDI) for considering these countries as cases. The Human Development Report (2017) revealed that although, Canada has higher HDI (0.926) but there is not much difference between Turkey (0.792) and Iran (0.798) while employment vulnerability, work, gender, human security, communication and mobility in all three considered economies are same, thus, these three countries are considered for the purpose of study.

Ducker (1998) argued that there is a visible shift in the paradigm of managerial literature with the passage of time. Habib (2011) stated, "one of the most significant changes in paradigm of modern business management is that individual businesses no longer compete as solely autonomous entities, but rather as supply chains. Business management has entered the era of inter-network competition and the ultimate success of a single business will depend on management's ability to integrate the company's intricate network of business relationships". Hence, it is important in explaining the concepts of intricated network theory. Relational view theory of firm's dyads and network 
in the supply chain management has been used often to understand strategic supply chain management. Within the complex competitive environment, due to flexible intricated approach there is often a usage of the relational view theory in the SCM (Dyer and Singh, 1998). Nevertheless, firm's dyads and network are significant in understanding the business dynamics and firm's overall performance (Lavie, 2006).

Resource-based theory is also used for understanding the supply chain management's functionality, but it is limited in explaining the higher overall performance within the business in order to attain competitive advantage (Blanchard, 2010). Nonetheless, "from the unit of analysis, this is evident that RBV fails to confirm the competitive advantage while the dyads and network theory as part of relational view reveals that the organisations having higher level of networking have more strong grip on the market as they remain competitive in reducing the inventory time and improve the quality of the work through shared expertise" (Ramsay, 2001). Barney (2012) argued that many aspects of the strategic supply chain management are implemented and understood by using the relational view perspective (Barney, 2012). Yet, through adoption of relational view theory of firm's dyads and network for investigating the supply chain management in the manufacturing and services industry operating in the cross-cultural context is under research. The comparative mode to attain multinational perspective is effective in delimiting the region specificity by offering superior knowledge in broader context. Hence, the gap in the literature is filled by offering evidence from cross-cultural comparative perspective. In addition to that, the resource-based view (RBV) has a biggest drawback of using "unit of analysis" by primarily focusing on internal resource whereas there is need to find a right-fit between internal and external attributes associated with strategic supply chain management. This limitation of $\mathrm{RBV}$ to be overcome through this study.

The study aim is, "to examine the mediating effect of strategic supply chain management within the small businesses on the sustainable operations (environmental and social sustainability) from multinational perspective".

\section{Literature Review}

Higher variations and inconsistent findings are traced in the considered wide range of supply chain management related empirical studies. For instance, Truong et al. (2017) found that the small businesses operations are significantly affected by the strategic SCM. Nevertheless, same study did not find the small businesses operations in relation to social and environmental sustainability.

The strategic SCM components including practices, determinants, and supporting factors are found to add competitive advantage to operations through cost reduction and effective adoption of sophisticated technology
(Arend and Wisner, 2005) while still less is researched from the sustainability perspective.

SCM practices are not always right fit for SMEs because of the challenges related to proper execution and implementation as the operations are frequently carried on small scale whereas the rate of investment remains lower that further weakens the strategic SCM execution (Arend and Wisner, 2005). Nevertheless, plethora of research found that SMEs' sustainable operations as well as overall performance improved due to strategic SCM because it helps the businesses in keeping a steady focus on the activities to ensure they remain competitive, transparent, and sustainable (Thakkar, Kanda and Deshmukh, 2011; Tvaronavičienė, Razminienė and Piccinetti, 2015). Strategic supply chain has a positive linkage with the factors supporting supply chain management (Awheda et al. 2016; Malik et al. 2014). On the other hand, Kherbach and Mocan (2015) found statistically no significant impact of supporting factors of SCM on the strategic supply chain management within the SMEs. Having said that, there is no conclusive evidence confirming the nature of relationship from multinational context.

Hypothesis 1 - Strategic supply chain management of small businesses is significant positively affected by factors supporting SCM in Iran, Turkey, and Canada.

However, although, often SMEs perceive that strategic SCM is linked with the process of ensuring higher satisfaction of the consumers through large investment in advanced information technology (Kumar, Singh and Shankar, 2015), instead of taking into consideration the strategic SCM's impact on the environmental and social sustainability (separate dimensions of sustainable operations). Interestingly, plethora of empirical studies have frequently used the terminologies such as "small and medium-sized enterprises", "strategic management" and "supply chain" in their titles but failed to explain in-depth the impact of strategic SCM in relation to sustainability (Kot et al. 2018).

Zowada (2011) argued that SMEs via its SCM channelized activities and performances is the way to tackle the challenges related to environmental and social sustainability. In this regard, practices of supply chain management are highly invaluable for the SMEs. Adaptability, flexibility, and low-cost strategies so that environmental challenges along with fulfilment of requirements of the consumers are vital features that to some extent facilitate business to sustain stable positioning in the environment" (Zowada, 2011). SMEs support functioning is vital in linking activities chain in sustainable and desired manner (Kisperska-Moroń, Klosa, Świerczek and Liniecki, 2010). Interestingly, key performance indicators (KPIs) are also important in determining the impact of SCM activities within the SMEs (Dumitrascu and Hila, 2017). Nevertheless, considering the challenges of environmental and 
social sustainability, the KPIs are less significant and effective because every organisation is different from one another.

"Literature provide the insight regarding services, quality, speed and value formation for the end-consumers are some of the dimensions to measure the strategic outlook and performance of SCM" (Ghicajanu, 2014). These aforementioned dimensions are most appropriate way to explain the business model and solutions for meeting unique external environmental challenges (Ghicajanu, 2014). Thus, it is found that open and flexible approach for redesigning and restructuring activities of supply chain are part of strategic SCM so that various external challenges could be dealt. Procter \& Gamble (P\&G) is one of the examples that has modified supply chain activities so that SCM operates in effective and efficient way to cope up with environmental challenges (Sundarakani, 2006).

Vasiliu and Dobrea (2013) carried out a research on issues and challenges related to SCM in different organisations, yet their findings are inconclusive because it fails to explain the causes for lower sustainable impact in the presence of integrated and incorporated activities. Additionally, Dumitrascu and Hila (2017) highlighted the drawback of Vasiliu and Dobrea's research that sample size is relatively small for drawing comprehensive conclusion. Nonetheless, Diaconu and Alpopi (2014) argued that SCM has both; strengths and weaknesses when opts for being more strategic and rational in its approach to deal with the environmental uncertainties. Same study argued that coordination, measurements, IT support, processing pattern and strategic orientation have its pros and cons. Nevertheless, at times the strategic SCM is highly effective in enhancing services level yet end short in reducing the negative impact on the operational environment (Diaconu and Alpopi, 2014). Hence, communication needs as well as SCM supporting factors are required to be improved so that sustainable desired operations develop and reduction in the adverse impact on external stakeholders (Diaconu and Alpopi, 2014).

Different organisations use a peripheral tool "Enterprise Resource Planning" (ERP) in order to have financial and other resources being used highly effectively, although, the operations and process of SCM does not improve significantly because of ERP (Țarţavulea and Petrariu, 2013). Conversely, Kherbach and Mocan (2015) argued that large enterprises have advantage over the SMEs because of the tendency to use human, technological, and financial resources for reducing negative effect on the external environment. The organisational flexibility has a tendency of improving the effectiveness in meeting and fulfilling the requirements of the market and ensure the reduction in the negative impact on the operational environment (Kherbach and Mocan, 2015).

Although, however the Oracle survey on IDG connect was executed in four different regions, namely, (a) Asia Pacific, (b) Europe, Middle East and Africa (EMA), (c)
Central and South America and (d) North America for examining the cloud-based SCM solutions having an impact of the societies and environment (Oracle, 2016). Findings showed that this strategic move leads to increase operational efficiency and productivity, reduction on operational cost while enabling businesses to deal with different types of environmental challenges (Oracle, 2016). However, the work of Lorentz, Touli, Solakivi and Ojala (2013) found that IT components of several types as part of strategic SCM are not always effective in the reduction on negative impact on social and environmental sustainability. In fact, they become a barrier for smooth flow of operations. Despite mix evidences, there are no conclusive evidence about the practices affecting strategic supply chain management in different economies. Therefore, hypothesis 2 is developed:

Hypothesis 2 - Strategic supply chain management of small businesses is significant positively affected by practices of SCM in Iran, Turkey, and Canada.

Fung, Morton and Chong (2010) argued that the environmental sustainability improves due to channelizing and executing the environmental-friendly policies and practices within the supply chain management process. However, Harms (2011) found the obligatory incorporation of environmental and social dimensions within the SCM operations is effective in the expansion of diverse socio-economic aspects. Having said that, yet the research area is under studied because there is no conclusive evidence about the environmental and social sustainability (separate dimensions of sustainability) linkage with the strategic supply chain management in SMEs within different types of economies.

The strategic SCM of SMEs are significant affected by the determinants whereas practices are non-significant in doing so (Harasi, 2015). There is inconclusive evidence regarding the varying impact of strategic SCM on social and environmental sustainability in emerging-middle ranged-developed economies. In the absence of appropriate strategic SCM, there is negative impact on the social sustainability of the organisation (Awheda, Rahman, Ramli and Arshad, 2016; Malik, Musa, Ahmad and Mohamad, 2014; Mani, Agrawal and Sharma, 2015). "The operational efficiency tends to reduce to negative affect of inadequate strategic SCM on social sustainability" (Mani et al. 2015).

The previous empirical studies showed that determinants of supply chain management have a significant positive impact on the strategic supply chain management among different SMEs (Arend and Wisner, 2005; Koh et al. 2007). Furthermore, work of Harsi (2015) revealed that different organisational components (determinants) develop a strong positive impact on the strategic supply chain management for the SMEs because of the nature of these organisational component are un-observe variable. Still, there is no clear evidence from the previous studies 
confirming the nature of impact of determinants of SCM on the strategic supply chain management. In addition to that, there are no studies to assess the relationship from the multinational context. Hence, in the light of identified literature, third hypothesis is drawn:

Hypothesis 3 - Strategic supply chain management of small businesses is significant positively affected by determinants of SCM in Iran, Turkey, and Canada.

The study of Koh et al (2007) found no statistically significant impact of strategic SCM on the operational efficiency of SMEs as well as found non-significant impact on the environmental and social sustainability. This indicates that two distinctive studies found different results, yet both found non-significant impact in terms of environmental and social sustainability. Having said that, those studies were single cases offering limited generalizability whereas comprehensive cross-sectional research is still under research because the earlier studies have smaller sample size and largely focused on region-specificity. To larger extent, available literature concentrated on the direct relationship between strategic SCM and SMEs' performance, while still under research is the strategic SCM's mediating effect on the environmental and social sustainability, especially in the context of comparison between advanced, middle-range, and emerging economy.

Kherbach and Mocan (2015) study found that practices, supporting factors and determinants of SCM are very effective in meeting the needs of consumers, enhancing organisational efficiency and dealing with various environmental challenges. Thus, the strategic SCM is pivotal in dealing with the challenges of environment. Nonetheless, the study falls short in explaining the mediating effect on environmental and social sustainability resulting from strategic SCM. Hence, the area is under research when the mediating role of strategic SCM on sustainability is to be considered, especially in multinational context because studies largely focused on direct linkage of strategic SCM instead of considering it as a mediator. The identified gap in the existing literature drives this research to fill it by offering multinational perspective within one construct. Following hypotheses are developed.

Hypothesis 4 - Strategic supply chain management of mediates environmental sustainability in Iran, Turkey, and Canada.

Hypothesis 5 - Strategic supply chain management mediates social sustainability in Iran, Turkey, and Canada.

\section{Research Framework}

The research framework of this study includes independent variables, namely. Factors supporting SCM, practices of SCM and determinants of SCM while environmental and social sustainability are the dependent variables. Strategic supply chain management is the mediating variable. The variables of interest are illustrated below:

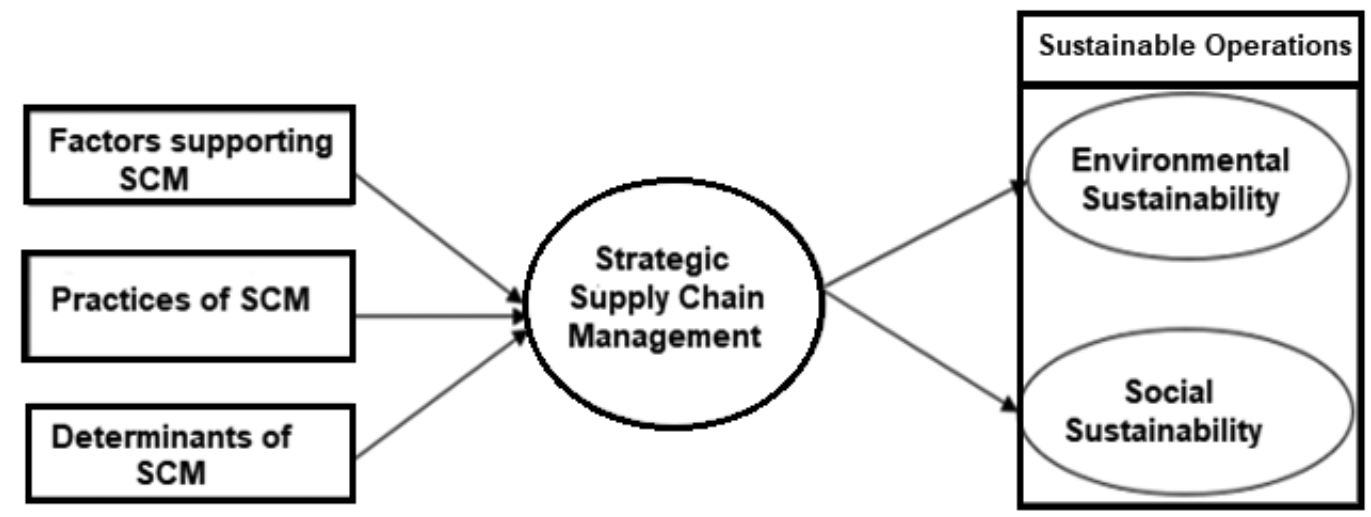

Figure 2: Own-illustrated research framework 


\section{Research Methodology}

This comparative cross-sectional research comes under scientific paradigm thus, have critical realism ontology and objective epistemology to numerically express the social reality. Mackenzie and Knipe (2006) explained that positivism philosophy is considered for the research that focuses on attaining the factual truth by means of numerically expressing the relationship between variables of interest. Independent variable "factors of SCM" is formed of five factors on the scale of 1-to-5 (1=doesn't matter, $2=$ unimportant, $3=$ neutral, $4=$ important and $5=$ very important). Concentration on end consumers, organisational structure, importance of IT, knowledge sharing, and trust and openness are the factors supporting SCM (for detail see Appendix). Second variable on same scale is "determinants of SCM" that contains seven questions. Global competitiveness, customer needs, cooperation, integration process, and cost reduction were the factors constituting determinants of supply chain management (for details see Appendix). Third variable "practices of SCM" contains eight questions on 1 -to-5 ( $1=$ no implementation, $2=$ low level of implementation, $3=$ partial implementation, $4=\mathrm{im}$ plementation, and $5=$ full implementation) scale. In line internal strategy with Supply chain strategy, sustainability, coordination and communication, and standardized guidelines are factors determining the practices of supply chain management (for details, see Appendix).

The factors, determinants, and practices of SCM along with the social and environmental sustainability scale is adopted from the survey of Kot et al (2018) as it has been used previously in different countries. Both dependent variables of the study, "environmental" and "social sustainability" contained six questions each on the scale of 1-to-5 (1=doesn't matter, 2=unimportant, 3=neutral, 4=important and 5=very important). Environmental sustainability contained factors related to environmental-friendly, waste reduction, reduction of negative impact, and creating environmental awareness whereas ethical standards, community related operations, safety standards, and poverty reduction are factors for social sustainability that combined together forms sustainable operations (See Appendix for construct of variables).

Strategic SCM contains five questions on the scale of 1-to-5 (1=Strongly disagree, $2=$ disagree, $3=$ neutral, $4=$ agree, $5=$ strongly agree). Harasi's (2015) scale is used to measure the strategic supply chain management, containing intern-organisational communication, cross-organisational team, strategic planning and long-term orientation (for details see Appendix).

Hyman, Lamb and Bulmer (2006) stated that the adoption of pre-existing questionnaire helps researchers in ensuring higher construct and content validity. Inter-rater and test-re-test reliability is availed by using pre-existing questionnaire (Haque and Aston, 2016; Healy and Perry, 2006).
Hofstede's cultural dimensions were one of the criteria for the selection of three distinctive countries. Moreover, the HDI was another criterion for this selection. Higher similarity in employment vulnerability, work, gender, human security, and communication and mobility in all three considered economies are same, thus, these three countries are considered for the purpose of study. According to the official report of Senate Canada (2013), foreign affairs and international trade has strengthened the relationship between Canada, Turkey, and Iran. There has been collaboration and cooperation to improve the relations and trade. Since, there has been trade, production and services promoting the mutual supply chain activities therefore, these three countries have been considered cases.

Total 610 SMEs participated through one respondent per organisation. For fair representation, the strategy of Haque, Aston and Kozlovski (2018) was adopted, therefore, purposive sampling technique was employed to have fair representations in all three countries because in present scenario other sampling techniques were impractical and costly. Minimum 200 each is a target selection in distinctive geographic regions. Total 202 from Turkey whereas 204 each from Iran and Canada participated. Haque, Faizan and Cockrill's (2017) strategy was considered to ensure over 200 respondents participate in the comparative study. The response rate is $56.38 \%$ as total 1050 survey questionnaires were circulated (350 in each economy).

The strategy of Haque et al. (2018) was adopted by combining purposive, referrals, networking, and connection were sampling techniques used in this study to avoid over reliance on one specific technique. The list of registered SMEs was attained from the official ministry portal while questionnaire was formed on Googledoc and circulated through networking and connections. Smart partial least square structural equation (PLS-SEM) modeling is used for the data analysis.

All ethical considerations were maintained during and after research commencement and as part of it, there was no disclosure of respondent's personal detail to general public and participants were informed about the purpose of research.

\section{Results Analysis}

\subsection{Descriptive Statistics}

It is found that majority of the small businesses have a workforce ranging between 50-250 (52.5\%), operating for 'more than 15 years' $(42 \%)$, followed by ' 8 to 15 years' $(38 \%)$. This reflects that small businesses in considered economies have been active for a longer time duration. Majority of SMEs are involved in logistics and transportation $(30.4 \%)$, followed by clothing and textile $(28 \%)$ and 
cars and automotive (13.7\%) whereas majority of respondents are "Director of Logistics" (29\%), followed by "Marketing Director" (22\%) and "Owner" (18\%).

\subsection{Measurement model}

Henseler et al.'s (2009) suggestion regarding the usage of prominent statistical method for primary data analysis has been considered. Imran, Hameed and Haque (2018) explained that two major sections of statistical analysis include; measurement model assessment and structural model assessment. "The measurement model assessment is the first step to assess the model's validity before performing structural model assessment. As part of measurement model, the reliability is assessed through Cronbach's alpha and composite reliability while Average Variance Extracted (AVE) through factor loadings ae considered for external consistency to form convergent validity" (Imran et al. 2018). "Convergent validity, a parameter frequently utilized in social sciences research, refers to the degree to which two measures of constructs that theoretically should be related are in fact related" (Imran et al. 2018). A value less than 0.40 on factors loadings are excluded from the scale while only above 0.40 is included as it indicates the acceptable validity (Hair et al. 2016). Therefore, four factors are considered on all the variables of interest because they scored over 0.4. Acceptability is determined through Cronbach's alpha $(\alpha=<0.70)$, composite reliability $(\mathrm{C} . \mathrm{R}=<0.70)$ and Average Variance Extracted $(\mathrm{AVE}=<0.50)$. Item loading values and AVE are presented visible in figure 3, 4 and 5 for considered economies while Table 1 contains Cronbach's alpha $(\alpha)$, composite reliability (C.R), and Average Variance Extracted (AVE), which are all found satisfactory. Table 2 contains discriminant (external) validity by following Fornell and Larcker's (1981) criteria.

Internal consistency is acceptable because Cronbach's alpha $(\alpha)$ and composite reliability (C.R) for all items in Iran, Turkey and Canada is above 0.7 (Table 1). The model is acceptable because Average Variance Extracted (AVE) is found to be greater than 0.5. External validity is measured through cross loadings by using Fornell and Larcker's (1981) criteria. "The AVE of the exogenous (latent) variables higher than the extracted square root average variance reflects results validity" (Fornell and Larcker, 1981). All three countries are found to be greater than 0.50 , thus, all the constructs are acceptable (Table 2).

Table 1: Measurement model (results)

\begin{tabular}{lccccccccc}
\hline \multirow{2}{*}{ Constructs } & \multicolumn{3}{c}{ Iran } & \multicolumn{3}{c}{ Turkey } & \multicolumn{3}{c}{ Canada } \\
\cline { 2 - 10 } & $(\alpha)$ & CR & AVE & $(\alpha)$ & CR & AVE & $(\alpha)$ & CR & AVE \\
\hline Factors supporting & 0.817 & 0.732 & 0.521 & 0.721 & 0.826 & 0.601 & 0.988 & 0.861 & 0.682 \\
SCM & & & & & & & & & 0.762 \\
Practices of SCM & 0.710 & 0.731 & 0.613 & 0.760 & 0.765 & 0.602 & 0.771 & 0.785 & 0.656 \\
$\begin{array}{l}\text { Determinants of SCM } \\
\text { Strategic supply chain }\end{array}$ & 0.723 & 0.727 & 0.513 & 0.749 & 0.754 & 0.623 & 0.756 & 0.766 & 0.629 \\
management & 0.766 & 0.717 & 0.545 & 0.759 & 0.728 & 0.687 & 0.796 & 0.798 & 0.743 \\
$\begin{array}{l}\text { Environmental susta- } \\
\text { inability }\end{array}$ & 0.711 & 0.776 & 0.607 & 0.715 & 0.767 & 0.601 & 0.746 & 0.863 & 0.644 \\
Social sustainability & 0.832 & 0.736 & 0.561 & 0.718 & 0.737 & 0.588 & 0.751 & 0.762 & 0.615 \\
\hline
\end{tabular}


Table 3: Discriminant Validity (Fornell-Larcker criterion)

\begin{tabular}{|c|c|c|c|c|c|c|}
\hline Constructs & $\begin{array}{l}\text { Determinants } \\
\text { of SCM }\end{array}$ & $\begin{array}{l}\text { Factors } \\
\text { supporting } \\
\text { SCM } \\
\end{array}$ & $\begin{array}{l}\text { Practices } \\
\text { of SCM }\end{array}$ & $\begin{array}{c}\text { Strategic } \\
\text { supply chain } \\
\text { management }\end{array}$ & $\begin{array}{l}\text { Social susta- } \\
\text { inability }\end{array}$ & $\begin{array}{c}\text { Environmental } \\
\text { sustainability }\end{array}$ \\
\hline & & & & Iran & & \\
\hline Factors supporting SCM & 0.541 & & & & & \\
\hline Practices of SCM & 0.703 & 0.624 & & & & \\
\hline Determinants of SCM & 0.627 & 0.563 & 0.671 & & & \\
\hline $\begin{array}{l}\text { Strategic supply chain } \\
\text { management }\end{array}$ & 0.659 & 0.571 & 0.572 & 0.595 & & \\
\hline $\begin{array}{l}\text { Environmental sustaina- } \\
\text { bility }\end{array}$ & 0.595 & 0.651 & 0.609 & 0.633 & 0.515 & \\
\hline \multirow[t]{2}{*}{ Social sustainability } & 0.528 & 0.613 & 0.65 & 0.641 & 0.561 & 0.663 \\
\hline & & & & Turkey & & \\
\hline Factors supporting SCM & 0.632 & & & & & \\
\hline Practices of SCM & 0.611 & 0.721 & & & & \\
\hline Determinants of SCM & 0.517 & 0.569 & 0.626 & & & \\
\hline $\begin{array}{l}\text { Strategic supply chain } \\
\text { management }\end{array}$ & 0.518 & 0.565 & 0.541 & 0.526 & & \\
\hline $\begin{array}{l}\text { Environmental sustaina- } \\
\text { bility }\end{array}$ & 0.658 & 0.525 & 0.651 & 0.518 & 0.522 & \\
\hline \multirow[t]{2}{*}{ Social sustainability } & 0.672 & 0.521 & 0.502 & 0.511 & 0.517 & 0.519 \\
\hline & & & & Canada & & \\
\hline Factors supporting SCM & 0.711 & & & & & \\
\hline Practices of SCM & 0.712 & 0.814 & & & & \\
\hline Determinants of SCM & 0.732 & 0.698 & 0.755 & & & \\
\hline $\begin{array}{l}\text { Strategic supply chain } \\
\text { management }\end{array}$ & 0.765 & 0.754 & 0.571 & 0.697 & & \\
\hline $\begin{array}{l}\text { Environmental sustaina- } \\
\text { bility }\end{array}$ & 0.799 & 0.793 & 0.656 & 0.699 & 0.763 & \\
\hline Social sustainability & 0.622 & 0.727 & 0.737 & 0.789 & 0.792 & 0.724 \\
\hline
\end{tabular}

In second part, the research hypotheses developed from the available literature are tested through the structural model. Using structural model assessment, the research findings are attained.

\subsection{Structural model assessment}

Structural model assessment is used to examine the relationship between research variables. For testing hypotheses, we used mainly t-value to reject or retain hypotheses.
The threshold $\mathrm{t}$-value $=1.96$ at the 0.05 level of significance, hence, $t$-value above it is significant while below it will be non-significant. In the same vein, the p-value of less than 0.05 reflects statistically significant relationship. Moreover, R2 indicates the predictors (determinants of SCM, factors supporting SCM, practices of SCM, causing variability in dependent variable "sustainable operations" (environmental sustainability and social sustainability) while (f2) determines the size effect of the relationship. 


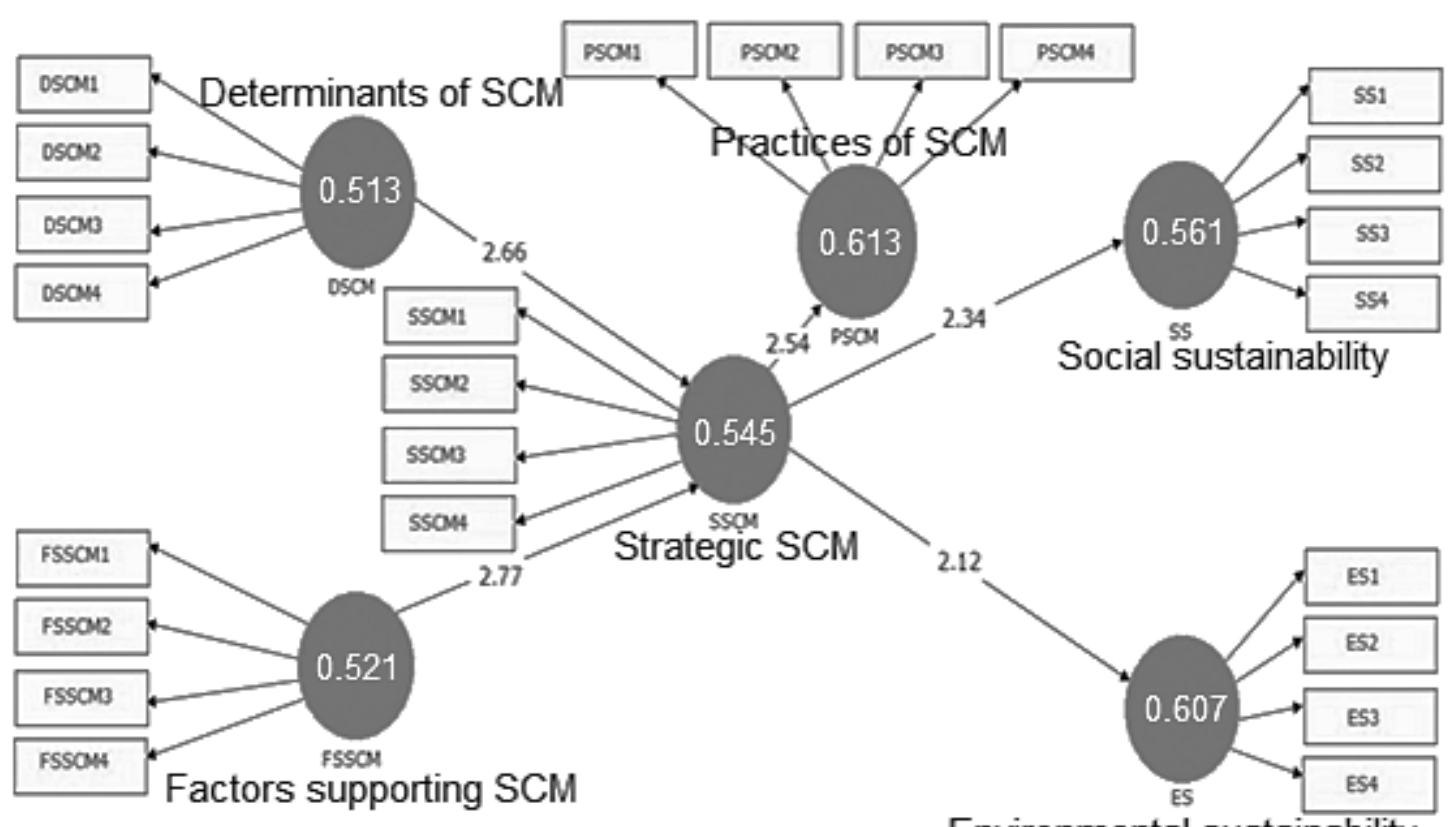

Environmental sustainability

Figure 3: Factor loading reflecting AVE and t-values attained through structural model - Iran

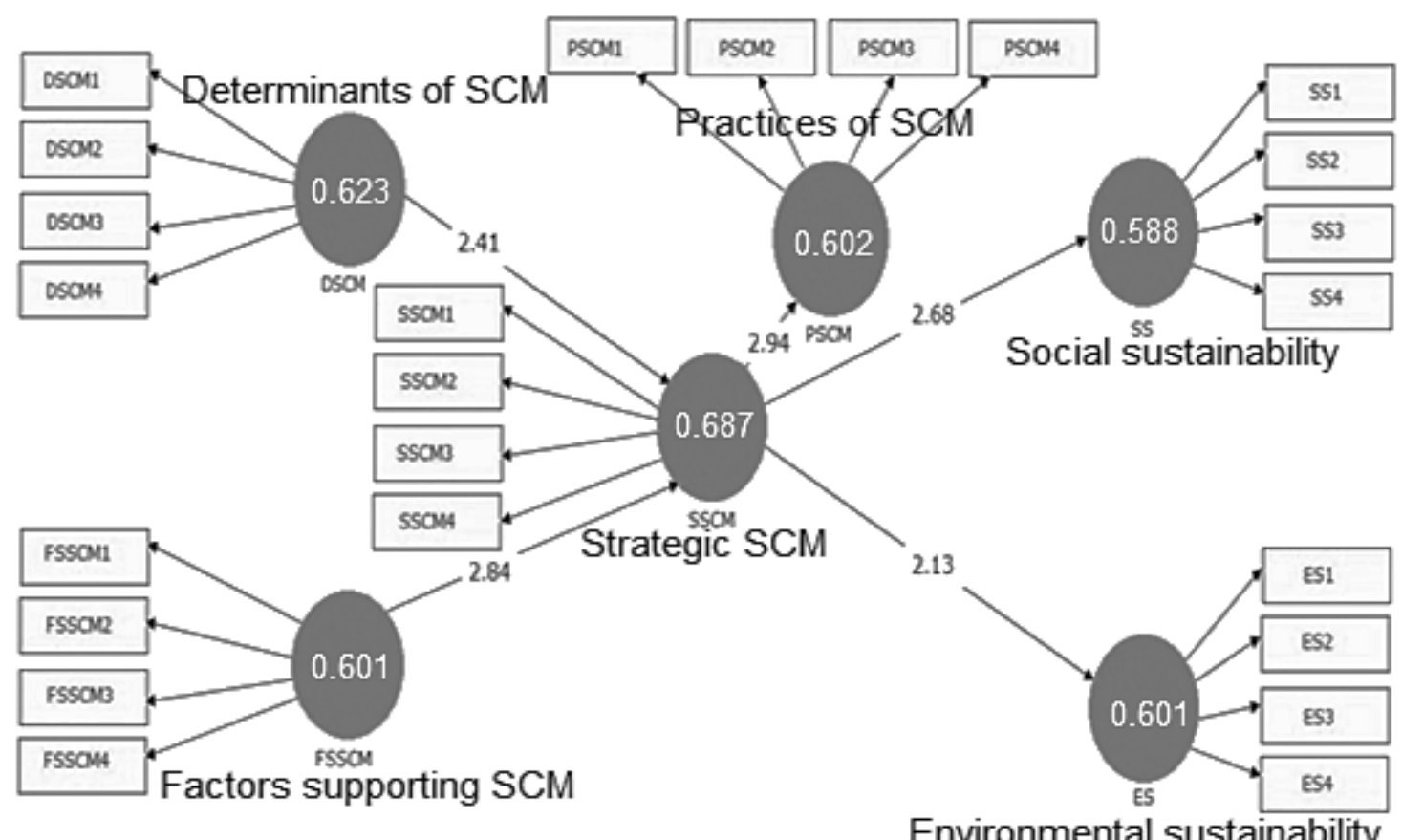

Environmental sustainability

Figure 4: Factor loading reflecting AVE and t-values attained through structural model-Turkey 


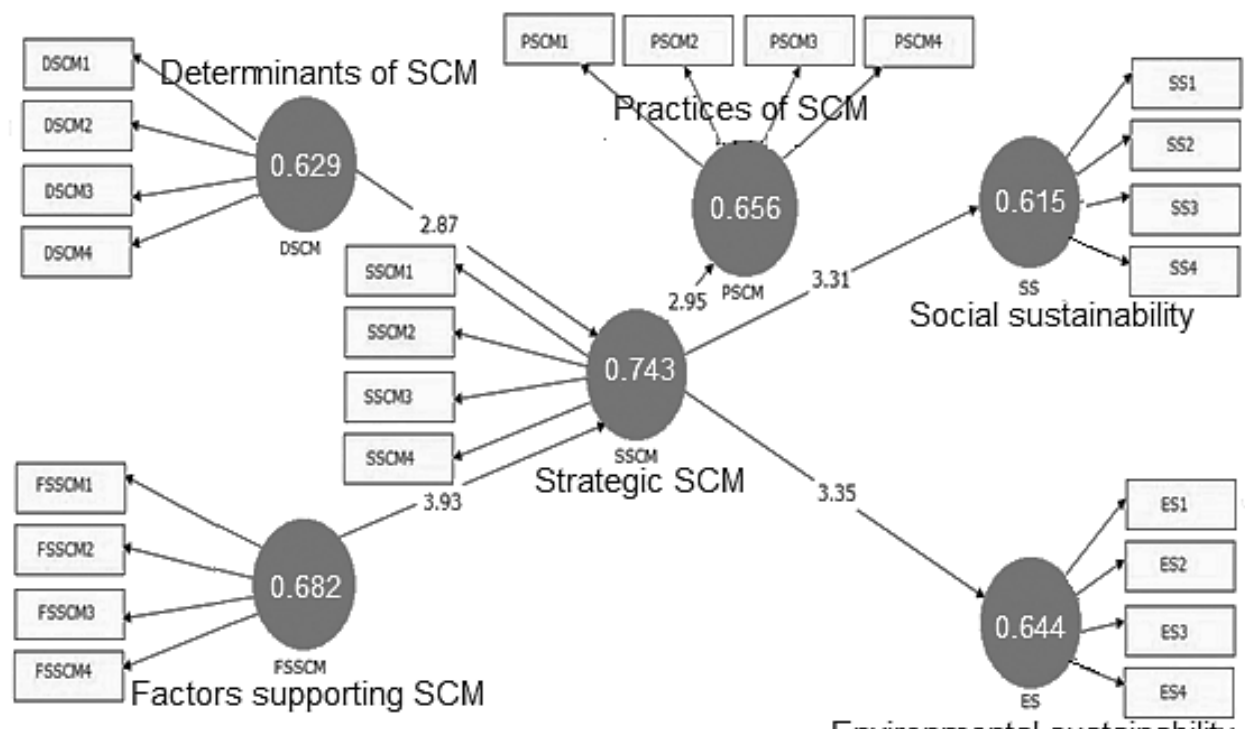

Environmental sustainability

Figure 5: Factor loading reflecting AVE and t-values attained through structural model-Canada

Table 4: Findings of Structural Model

\begin{tabular}{|c|c|c|c|c|c|c|}
\hline Hypotheses & $(\beta)$ & SD & t-Value & P-value & $f^{2}$ & $R^{2}$ \\
\hline \multicolumn{7}{|c|}{ Iran } \\
\hline H1: Factors supporting SCM-> Strategic SCM & 0.61 & 0.22 & 2.77 & 0.000 & 0.15 & 0.62 \\
\hline $\mathrm{H} 2$ : Practices of SCM -> Strategic SCM & 0.79 & 0.31 & 2.54 & 0.000 & 0.22 & 0.66 \\
\hline H3: Determinants of SCM -> Strategic SCM & 0.88 & 0.33 & 2.66 & 0.000 & 0.16 & \\
\hline H4: Strategic SCM -> Environmental sustainability & 0.66 & 0.31 & 2.12 & 0.000 & 0.36 & \\
\hline H5: Strategic SCM -> Social sustainability & 0.54 & 0.23 & 2.34 & 0.000 & 0.35 & \\
\hline \multicolumn{7}{|c|}{ Turkey } \\
\hline H1: Factors supporting SCM-> Strategic SCM & 0.71 & 0.25 & 2.84 & 0.000 & 0.16 & 0.59 \\
\hline $\mathrm{H} 2$ : Practices of SCM $->$ Strategic SCM & 0.64 & 0.31 & 2.94 & 0.000 & 0.24 & 0.68 \\
\hline H3: Determinants of SCM -> Strategic SCM & 0.82 & 0.34 & 2.41 & 0.000 & 0.17 & \\
\hline H4: Strategic SCM -> Environmental sustainability & 0.49 & 0.23 & 2.13 & 0.000 & 0.37 & \\
\hline H5: Strategic SCM -> Social sustainability & 0.51 & 0.19 & 2.68 & 0.000 & 0.35 & \\
\hline \multicolumn{7}{|c|}{ Canada } \\
\hline H1: Factors supporting SCM- $>$ Strategic SCM & 0.59 & 0.15 & 3.93 & 0.000 & 0.18 & 0.67 \\
\hline H2: Practices of SCM -> Strategic SCM & 0.68 & 0.23 & 2.95 & 0.000 & 0.26 & 0.69 \\
\hline H3: Determinants of SCM -> Strategic SCM & 0.89 & 0.31 & 2.87 & 0.000 & 0.19 & \\
\hline H4: Strategic SCM -> Environmental sustainability & 0.57 & 0.17 & 3.35 & 0.000 & 0.39 & \\
\hline H5: Strategic SCM -> Social sustainability & 0.96 & 0.29 & 3.31 & 0.000 & 0.36 & \\
\hline
\end{tabular}

Note: $* * * \mathrm{p}<0.1, * * \mathrm{p}<0.05, \mathrm{~ns}=$ nonsignificant $(\mathrm{p}>.05)$ (Two Tail) 


\section{Discussion}

Strategic supply chain management is statistically significantly affected by the factors supporting SCM in all three countries (See Table 4, H1). We fail to reject hypothesis 1. It confirms that factors supporting SCM in all three considered countries affect positively the strategic SCM of small businesses. Our findings are aligned with the works of Awheda et al. (2016) and Malik et al. (2014) because mentioned studies found positive linkage between considered variables while our findings partially differs with Kherbach and Mocan's (2015) findings as their study found non-significant impact of supporting factors on the Strategic SCM within SMEs. Present findings offer a new insight by confirming the positive linkage between considered variables from the multinational perspective. Deviation from standard by 1-unit led to create a positive impact by supporting SCM factors in strategic SCM in Small businesses (Iran--> $\beta=0.61$, Turkey-- $>\beta=0.71$, Canada-- $>\beta=0.59$; Table 4).

Strategic SCM of Small businesses is significant positively affected by the practices of SCM in all three countries (See Table 4, H2). Based on obtained findings, we fail to reject hypothesis 2. The work of Koh et al. (2007) is confirmed that practices of SCM is positively affecting the strategic SCM that further increases SME's operational efficiency. Since we found no variations within the strategic SCM in different countries despite deferring practice standards, thus, the work of Dumitrascu and Hila (2017) and Ghicajanu (2014) is contradicted. Interestingly, adaptive approach within the practices of SCM is higher effective in enhancing the strategic planning as well as operational efficiency is the argument posed by Faizan and Haque (2015), which to some extent is supported. Using funnel approach, it is found that adaptive approach used by business in all three countries have much improved strategic SCM. Furthermore, practices of SCM causes positive variation in all three countries (Iran--> $\beta=0.79$, Turkey--> $\beta=0.64$, Canada-- $>=0.68$; Table 4).

Strategic SCM of Small businesses is significant positively affected by the determinants of supply chain management in all three countries (See Table 4, H3). Hence, we fail to reject hypothesis 3 . Our work supports the earlier work of Arend and Wisner (2005) and Koh et al. (2007) as we found positive linkage between strategic SCM and determinants of SCM within Small businesses. Additionally, it is confirmed that strategic SCM is explored through interlinked other organisational components because of being by nature un-observed variable, thus, we support the argument of Harsi (2015). The organisational component within this study is the determinants of SCM that creates positive impact on strategic SCM in Small businesses in all three considered countries. Furthermore, determinants of SCM's beta value $(\beta)$ are positive, reflecting that strategic SCM is positively affected by determinants of SCM with change in 1-unit of standard deviation (Iran-- $>\beta=0.88$, Turkey-- $>\beta=0.82$, Canada-- $>\beta=0.89$; Table 4). Nevertheless, there is not much difference, but from the comparative lens Iran and Turkey scored less than Canada.

After determining the different organisational components linkage with the Strategic SCM, next step is to measure the mediating effect of Strategic supply chain management on the environmental sustainability. It is found to have statistically significant positive mediating effect in all three countries (See Table 4, H4). Similarly, strategic SCM has a significant positive mediating effect on social sustainability in all three countries (See Table 4, H5). Therefore, we do not reject hypotheses 4 and 5.

Considering the environmental sustainability, we support the findings of Fung et al. (2002), Kherbach and Mocan (2015), and Zowada (2011) as we found strategic SCM mediates positively the environmental sustainability where we contradict the work of Awheda et al. (2016), Malik et al. (2014) and Mani et al. (2015) in this regard. We confirm the argument of Kot et al. (2018) that strategic supply chain management is effective in dealing with various types of environmental challenges. We further extend Kot et al.'s argument by confirming it from multinational perspective. Strategic SCM causes a positive variation in the environmental sustainability (Iran--> $\beta=0.66$, Turkey--> $\beta=0.49$, Canada $->\beta=0.57$; Table 4 ).

Moreover, our findings support the work of Harms (2011), Kherbach and Mocan (2015), Koh et al. (2007), and Zowada (2011) whereas oppose the Awheda et al. (2016), Ghicajanu (2014), Malik et al. (2014) and Mani et al. (2015) work by confirming positive linkage between strategic SCM and social sustainability. Strategic SCM causes positive variation in the social sustainability when there is an increase in 1-unit standard deviation (Iran--> $\beta=0.54$, Turkey-- $>\beta=0.51$, Canada-- $>\beta=0.96$; Table 4 ).

"The value of variance (R2) is a value that indicates that the variability in the independent variable causing the variation in dependent variable" (Chin, 1998). In Iran's Small businesses, $62 \%$ variations are caused by variable in environmental sustainability while $66 \%$ variation caused in social sustainability. In Turkey's small businesses, $59 \%$ in environmental sustainability is caused by variables while $68 \%$ variation in social sustainability. Lastly, in Canada $67 \%$ variation caused by variables in environmental sustainability whereas $69 \%$ in social sustainability. "The values of effect size (f2) are considered as small $(0.02)$, medium $(0.15)$ and large $(0.35)$ respectively" (Cohen, Cohen, West and Aiken, 2013). In present study, the size effects (f2) are moderate for determinants of SCM in Iran, Turkey and Canada $(0.16,0.17$ and 0.19$)$; factors supporting SCM $(0.15,0.16$ and 0.18$)$; and practices of SCM $(0.22,0.24$ and 0.26$)$. Furthermore, strategic SCM has a large size effect (f2) on social sustainability and environmental sustainability in Iran, Turkey and Canada (Social Sustainability (f2) $=0.35 .0 .35$ and 0.36 ; Environmental Sustainability (f2) $=0.36,0.37$ and 0.39 . See Table 4). 


\section{Conclusion}

\subsection{Findings}

The gathered data from the small businesses operating in Iran, Turkey, and Canada was to gain a multinational perspective about the strategic functioning of supply chain activities. In the light of statistical analysis, the conclusion is drawn that strategic supply chain management statistically significant positively mediates the sustainable operations (environmental and social sustainability). Hence, it is confirmed that irrespective of the type of economy, the strategic SCM positively mediate the environmental and social sustainability. Furthermore, the strategic supply chain management is significant positively affected by the factors supporting SCM, practices of SCM, and determinants of SCM. From the multinational perspective, the strategic SCM is highly effective in creating positive mediations while it has been affected positively by the practices, supporting factors and determinants (all organisational components) of supply chain management. The statistical test results also confirmed that the size effect (f2) is moderate for the impact of factors supporting SCM, practices of SCM, and determinants of SCM on the strategic SCM within the Small businesses. Moreover, strategic SCM is both; a significant mediator as well as found to have a large size effect (f2) on the environmental sustainability and social sustainability in multinational perspective. Interestingly, the nature and strength of the relationship between variables of interest are more visible as well as stronger in Canada (advanced economy) in contrast to Iran (emerging economy) and Turkey (middle ranged economy).

\subsection{Recommendations}

It is recommended that the Small businesses should opt for using advanced technology within the strategic supply chain management process. For commencing the operations, the use of enterprise resource planning (ERP) could be useful in attaining cost-effective operations because it will save time, money, and energy while effective usage of invaluable resources would be possible. This practical approach would help in improving organisational efficiency through strategic SCM process. The use of advanced technology in the evaluation of supporting factors and on-going practices and procedures shall be considered so that operational working efficiency improve further. Through funnel approach it was found that within the SCM operations, cross-team communication is an issue reducing the accuracy within the real time production. Considering the agenda, Faizan and Haque's (2015) strategy of using polar adaptive approach for linking all the departments and sub-units are recommended so that communication is improved, which would bring accuracy through exchange of information that would lead to bring higher precision the real time production.

Small businesses are part of the societies therefore it shall take appropriate steps to reduce its negative operational impact on the environment and societies. In this regard, a recommendation for strengthening the ties between Small businesses and their stakeholder is through network, collaboration, and communication so that shared resources and knowledge lead to ensure sustainable operations for the environment and societal. For managers, the Small businesses shall make it mandatory to exercise the environmental and social responsibility practices so that the business achieve strategic perspective of environmental and social sustainability. "Through sharing stakeholder network, the good spill-over effects for wider societies could be attained through promotion of socially responsible and environmentally responsible behaviour" (Bressan, 2014; Chwistecka-Dudek, 2016; Szczepańska-Woszczyna and Kurowska-Pysz, 2016).

\subsection{Contributions}

From theoretical perspective, our study enhances the existing knowledge by theorizing that strategic SCM has a positive mediating effect on the sustainable operations (environmental and social sustainability). It provides the international as well as cross-cultural perspective by offering the findings from three distinctive economies, thus, offers the wider generalizability by delimiting the region-specificity. Since, the use of strategic SCM (as a common mediator), this study is pioneer in offering the theoretical framework to investigate the social and environmental sustainability as separate attributes while considering the range of differing economies whereas previously these dimensions were under research. Thus, now there is a theoretical framework to further expand the scope of studies in this direction. From practical lens, the implication of present study is that now managers have scientific evidence for ensuring strategic SCM has a positive linkage with the supporting factors, practices, and determinants of SCM while strategic supply chain management further creates positive mediation in the sustainable operations (environmental and social sustainability). Furthermore, managers are given practical recommendations to adapt sustainable approach for maintaining higher level of operational efficiency. The study is also invaluable for the governments and policymakers to ensure that Small businesses are encouraged towards use of sustainable operations, so that sustainable Small businesses' ongoing operations have a positive social impact on the communities and societies. 


\subsection{Research limitations and future directions}

Despite our best possible efforts for carrying out comprehensive research, there is always something to improve in the future studies. We used cross-sectional design that limits the respondents' participation to only one time while future researchers shall consider the use of longitudinal panel study to have twice participation so that the variation within differing time lags could be determined. This would offer more concrete evidence with differing time lags by having more comprehensive research design. Moreover, the study is quantitative in nature while focusing on the factual truth whereas future researchers shall consider the use of qualitative methods so that there is useful truth. In other words, now the relationship is expressed in numeric so factual truth has been attained, it shall be further expanded by having useful truth to explore the in-depth phenomenon.

\section{Literature}

Arend, R. J., \& Wisner, J. D. (2005). Small business and supply chain management: is there a fit? Journal of Business Venturing, 20, 403-436, https://doi.org/10.1016/j.jbusvent.2003.11.003

Awheda, A., Rahman, M. N. A., Ramli, R., \& Arshad, H. (2016). Factors related to supply chain network members in SMEs, Journal of Manufacturing Technology Management, 27(2), 312335, https://doi.org/10.1108/JMTM-01-2015-0005

Barney, J.B. (2012). Purchasing, supply chain management and sustained competitive advantage: the relevance of resource-based theory, Journal of Supply Chain Management, 48(2), 3-6, https://doi.org/10.1111/j.1745-493X.2012.03265.x

Blanchard, D. (2010). Supply Chain Management Best Practices, 2nd Edition, USA: John Wiley \& Sons. ISBN: 978-0-470-53188-4.

Bressan, A. (2014). Environmental and Social Responsibility within SMEs: Managerial Perspectives from Western Sydney, Australia, $\mathrm{PhD}$ Thesis, University of Western Sydney. Retrieved from: https://researchdirect.westernsydney.edu.au/islandora/object/uws\%3A31714/datastream/PDF/view

Chin, W.W. (1998). Commentary: Issues and opinion on structural equation modeling, JSTOR, 22: vii-xvi, http://doi.org/10249674

Chwistecka-Dudek, H. (2016). Corporate Social Responsibility: Supporters vs. opponents of the concept. Forum Scientiae Oeconomia, 4(4), 171-179.

Cohen J., Cohen P., West S.G., \& Aiken L.S. (2013). Applied multiple regression/correlation analysis for the behavioral sciences, London: Routledge.

Diaconu, D.M., \& Alpopi C. (2014). Strengths and weaknesses of current Supply Chain Management and initiatives for the future, Proceedings of the 8th International Management Conference "Management Challenges for Sustainable Development", November 6th-7th, Bucharest, Romania, 1165-1172.

Dumitrascu, O., \& Hila C.M. (2017). Actual state of knowledge in the field of Supply Chain Management, 8th International Conference on Manufacturing Science and Education - MSE 2017 "Trends in New Industrial Revolution", MATEC Web of Conferences 121, https://doi.org/10.1051/matecconf/201712107007.

Dyer, J.H., \& Singh, H. (1998). The relational view: cooperative strategy and sources of inter-organisational competitive advantage, Academy of Management Review, 23(4), 660-679, https://doi.org/10.2307/259056

Faizan, R., \& Haque, A. U. (2015). Bullwhip effect phenomenon and mitigation in logistic firm's supply chain: Adaptive approach by Transborder Agency, Canada. International Journal of Supply Chain Management, 4(4), 43-51.

Fornell, C., \& Larcker, D. (1981). Evaluating structural equation models with unobservable variables and measurement error, Journal of Marketing Research, 18, 39-50, https://doi.org/10.2307/3151312

Fung, R.Y.K., Morton, B., \& Chong, S. (2000). Environmental Sustainability in Supply Chain Management, In: Hayhurst D.R. et al. (eds) Proceedings of the 33rd International MATADOR Conference. Springer, London.

Ghicajanu, M. (2014). Open Innovation - A Solution in the Redesigning of Supplying Chain Management. Case Study in Innovation Networks from Procter \& Gamble, Supply Chain Management Journal, 5(2), 39-48. Available at https://scm-journal.com/past-issues $/$ ? issue $=$ supply-chain-management-journal-2014-volume-5-number-2 Habib, M.M. (2011). Supply Chain Management (SCM): Theory and Evolution. Supply Chain Management, Applications and Simulations. In. Tech Open Access, Croatia, September 2011, http://doi.org/10.5772/24573

Haque, A. U., \& Aston, J. (2016). A Relationship between Occupational Stress and Organizational Commitment of I.T Sector's Employees in Contrasting Economies, Polish Journal of Management Studies, 14(1), 95-105, http://doi.org/10.17512/pjms.2016.14.1.09

Haque, A. U., Faizan, R., \& Cockrill, A. (2017). The relationship between female representation at strategic level and firm's competitiveness: evidences from cargo logistic firms of Pakistan and Canada, Polish Journal of Management Studies, 15(2), 69-81, http://doi.org/10.17512/pjms.2017.15.2.07

Haque, A.U., Aston, J., \& Kozlovski, E. (2018). The impact of stressors on organisational commitment of managerial and non-managerial personnel in contrasting economies: Evidences from Canada and Pakistan, International Journal of Business, 23(2), 152-168. Available at http://www.craig. csufresno.edu/ijb/Volumes/Volume23/V232-4.pdf

Harms, D. (2011). Environmental Sustainability and Supply Chain Management - A Framework of 
Cross-Functional Integration and Knowledge Transfer, Journal of Environmental Sustainability, 1(1), Article 9, http://doi.org/10.14448/jes.02.0009, available at https://scholarworks.rit.edu/jes/vol1/iss1/9/

Harasi, M. (2015). Mediating Role of Strategic Supply Management on Performance, The 2014 International Conference on Agro-industry (ICoA): Competitive and sustainable Agro-industry for Human Welfare, Procedia - Agriculture and Agriculture Science, 3, 89-94.

Healy, M., \& Perry, C. (2000). Comprehensive criteria to judge validity and reliability of qualitative research within the realism paradigm, Qualitative Market Research, 3(3), 118-126, http://dx.doi.org/10.1108/13522750010333861

Henseler, J., Ringle, C. M., \& Sinkovics, R. R. (2009). The use of partial least squares path modeling in international marketing, Advances in Marketing, 20, 277-319, http://doi.org/10.1108/S1474-7979(2009)0000020014

Hofstede-insight (2018). Country Comparison Hofstede Cultural Dimensions. [Online]. Retrieved from: https://www.hofstede-insights. com/country-comparison/canada,iran,turkey/

Human Development Report (2017). Human Development Indicator for Turkey, Canada and Iran. [Online]. Retrieved from: http://hdr.undp.org/en/countries/profiles/

Hyman, L., Lamb, J., \& Bulmer, M. (2006). The Use of Pre-Existing Survey Questions: Implications for Data Quality, Proceedings of 2006 European Conference on Quality in Survey Statistics, [Online]. Retrieved from: https://ec.europa.eu/eurostat/documents/64157/4374310/22-Use-of-pre-existing-survey-questions-implications-for-data-quality-2006. pdf/e 953a39e-50be-40b3-910f-6c0d83f55ed4

Imran, M., Hameed, W.U., \& Haque, A.U. (2018). Influence of Industry 4.0 on the Production and Service Sectors in Pakistan: Evidence from Textile and Logistics Industries, Social Sciences, 7(12), 246, https://doi.org/10.3390/socsci7120246

Kherbach, O., \& Mocan, M.L. (2015). The importance of logistics and Supply Chain Management in the Enhancement of Romanian SMEs, SIM 2015 / 13th International Symposium in Management, [in:] Procedia - Social and Behavioral Sciences 221, 405413, http://doi.org/10.1016/j.sbspro.2016.05.130

Kisperska-Moroń D., Klosa E., Świerczek A., \& Liniecki R. (2010). Funkcjonowanie matych $i$ średnich firm produkcyjnych $w$ tańcuchu dostaw [Operation of small and medium-sized manufacturing companies in the supply chain]. Wyd. Uniwersytetu Ekonomicznego in Katowice, Katowice.

Kljucnikov, A., Belas, J., Kozubikova, L., \& Pasekova, P. (2016). The Entrepreneurial Perception of SME Business Environment Quality in the Czech Republic. Journal of Competitiveness, 8(1), 66-78, https://doi.org/10.7441/joc.2016.01.05

Koh, S. C. L., Demirbag, M., Bayraktar, E., Tatoglu, E., \& Zaim, S. (2007). The impact of supply chain management practices on performance of SMEs, In- dustrial Management \& Data Systems, 107(1), 103124, http://doi.org/10.1108/02635570710719089

Kot, S., Onyusheva, I., \& Grondys, K. (2018). Supply Chain Management in SMEs: Evidence from Poland and Kazakhstan, Engineering Management in Production and Services, 10(3), 23-36, available at https://content. sciendo.com/view/journals/emj/10/3/article-p23.xml

Kovács, G., Kot, S. 2016. New logistics and production trends as the effect of global economy changes. Polish Journal of Management Studies, 14(2), 115-126, http://doi.org/10.17512/pjms.2016.14.2.11

Kozubikova, L., Homolka, L., \& Kristalas, D. (2017). The Effect of Business Environment and Entrepreneurs' Gender on Perception of Financial Risk in the SMSs Sector. Journal of Competitiveness, 9(1), 36-50, http://doi.org/10.7441/joc.2017.01.03

Kumar, R., Singh, R. K., \& Shankar, R. (2015). Critical success factors for implementation of supply chain management in Indian small and medium enterprises and their impact on performance, IIMB Management Review, 27(2), 92104. https://doi.org/10.1016/j.iimb.2015.03.001

Lavie, D. (2006). The competitive advantage of interconnected firms: An extension of the resource-based view, The Academy of Management Review, 31(3), 638-658. https://doi.org/10.5465/amr.2006.21318922

Liberko, I., Bednarová, L., Hajduová, Z., \& Chovancová, J. (2015). Possibilities to optimize the logistics chain in the manufacturing plant. Polish Journal of Management Studies, 12(2), 103-113.

Lorentz, H., Touli, F., Solakivi, T., \& Ojala, L. (2013). Priorities and determinants for supply chain management skills development in manufacturing firms, Supply Chain Management: An International Journal, 18(4), 358-375, https://doi.org/10.1108/SCM-03-2012-0111

Liberko, I., Bednarová, L., Hajduová, Z., \& Chovancová, J. (2015). Possibilities to optimize the logistics chain in the manufacturing plant. Polish Journal of Management Studies, 12(2), 103-113.

Malik, S. N. A. A., Musa, H., Ahmad, S., \& Mohamad, N. (2014). The Factors influencing Supply Chain Disruptions on Supply Chain Performance in Small and Medium Enterprises, Journal of Technology Management and Technopreneurship, 2(2), 1-9.

Mani, V., Agrawal, R., \& Sharma, V. (2015). Social sustainability in the supply chain: analysis of enablers, Management Research Review, 38(9), 10161042, http://dx.doi.org/10.1108/MRR-02-2014-0037

OECD (2009). Top barriers and drivers to SME internationalisation. Report by the OECD Working Party on SMEs and Entrepreneurship, OECD. https://www.google.com/url? sa $=$ t\&rct $=\mathrm{j} \& \mathrm{q}=\&$ esrc $=\mathrm{s} \&$ source $=$ web\&c$\mathrm{d}=2 \& \mathrm{cad}=\mathrm{rja} \& \mathrm{uact}=8 \& \mathrm{ved}=2 \mathrm{ahUKEwjVs}-$ bOo85jkAhUG aQKHR9uBVYQFjABegQIABAB\&url=https $\% 3 \mathrm{~A} \% 2 \mathrm{~F} \% 2 \mathrm{~F}$ strathprints. strath. ac.uk\%2F15845\%2F\&usg=AOvVawlucXSGFyoQ6AcuZOSYYjWJ Oracle (2016). The Future for Cloud-based Supply Management Solutions. [Online] Retrieved from: 
http://www.oracle.com/us/products/applications/ idg-connect-report-infographic-3 101243 .pdf

Ramsay, J. (2001). "The resource-based perspective, rents, and purchasing's contribution to sustainable competitive advantage", Journal of Supply Chain Management, 37(3), 38-47, https://doi.org/10.1111/j.1745-493X.2001.tb00104.x

Senate Canada (2013). Standing Senate Committe on Foreign affairs and international trade. Building Bridge: Canada-Turkey Relations and Beyond. [Online]. Retrieved from: https://sencanada.ca/content/sen/Committee/411/aefa/rep/rep13jun13-e.pdf

Sundarakani, B., Vrat, P., \& Kumar, P. (2006). Assessing the challenges and opportunities of global supply chain management, International Journal of Value Chain Management, 1(2), 105-116.

Szczepańska-Woszczyna, K., \& Kurowska-Pysz, J. (2016). Sustainable business development through leadership in SMEs. Engineering Management in Production and Services, 8(3), 57-69, http://doi.org/10.1515/emj-2016-0024

Ţarţavulea, R.I., \& Petrariu, R.I. (2013). Logistics Market Statistics and Opinions about the Supply Chain Management in Romania, Amfiteatru Economic, $\quad X V(33)$ : 44-55, sociology.eu\%2Ffil es $\% 2$ F9_654\%2520Kot\%2520et\%2520al.pdf\&usg $=\bar{A}$ OvVaw2y3AZKA1CQ4x6r1BOEzdxX

Thakkar, J., Kanda, A., \& Deshmukh, S.G. (2011). Mapping of supply chain learning: a framework for SMEs. The Learning Organization, 18, 313332, http://doi.org/10.1108/09696471111132522

Thakkar, J., Kanda, A., \& Deshmukh, S.G. (2008). Supply chain management in SMEs: development of constructs and propositions. Asia Pacific Journal of Marketing and Logistics, 20, 97131, http://doi.org/.1108/13555850810844896

Truong, H. Q., Sameiro, M., Fernandes, A. C., Sampaio, P., Duong, B. A. T., Duong, H. H., \& Vilhenac, E. (2017). Supply chain management practices and firms' operational performance, International Journal of Quality \& Reliability Management, 34(2), 176193, https://doi.org/10.1108/IJQRM-05-2015-0072

Tvaronavičienè, M., Razminienè, K., Piccinetti, L. (2015). Approaches towards cluster analysis, Economics and Sociology, 8(1), 19-27, http://doi.org/10.14254/2071-789X.2015/8-1/2

Vasiliu, C., \& Dobrea, M. (2013). State of implementation of Supply Chain Management in companies in Romania, Amfiteatru Economic, XV(33), 180-196.

Zowada K., 2011. Logistyczne aspekty funkcjonowania matych $i$ średnich przedsiębiorstw [Logistic aspects of the functioning of small and medium enterprises]. In: A. Adamik (ed.) Kształtowanie konkurencyjności i przewagi konkurencyjnej małych i średnich przedsiębiorstw, C.H. Beck, Warszawa, 160-169.
Sebastian Kot, Ph.D. is currently associate professor in management and supply chain management and Vice Director of the Institute of Logistics and International Management at Faculty of Management, Częstochowa University of Technology. He is also extraordinary professor in North-West University, Faculty of Economic Sciences and IT, South Africa. He has taught a variety of undergraduate and graduate courses in the areas of logistics, supply chain management, international transportation. Prof. Kot has published widely, and his publications include books, book chapters, refereed journals' papers, conference proceedings. He is a Founder and Co-editor of Polish Journal of Management Studies, member of numerous journal scientific boards as well as reviewer. His research interests are in the areas of sustainable supply chain management, logistics, transportation and globalisation. ORCID ID: http://orcid.org/0000-0002-8272-6918.

Adnan ul Haque, DBA from the University of Wales TSD-London is currently an on-line mentor and research supervisor at oxford Brookes University for BA (Hons) students working on final research projects. He also offers lecturers at different educational institutions in the UK. He holds a Master of Business Administration (HRM) with distinction from the University of Sunderland and MPA (HRM) with distinction from the University of Karachi. He offers corporate training to MNC employees and present keynotes at international conferences. He is an HR consultant to Logistic firms in Canada. He has published widely in Scopus and ABS indexed journals. His research interest areas include; HRM, organisational behaviour, supply chain management, sustainability, stress, and leadership. ORCID ID: https://orcid.org/0000-0003-2051-8635.

Eugene Kozlovski, Ph.D. is Director of Studies for Doctoral Programmes at the University of Wales TSDLondon and Director for Research at the Dublin Centre for European Strategy. He also holds professorships and affiliations with many leading international business schools. Previously, he was Programme Director for e-Business in the University of Liverpool Management School, and Senior Research Fellow in UCL. His industrial engagements have included key Project Management roles at major EU R\&D consortia, and strategy and management consultancy to leading technology-led transnational companies. He is a Fellow of the British Higher Education Academy (FHEA) and received his Doctorate from University College London in 2003. ORCID ID: https://orcid.org/0000-0003-30621791. 


\section{Appendix: List of Measurement Items}

\section{Factors supporting SCM \\ Concentration on end consumers \\ FSSCM1: »Concentration on end consumers« Organisational structure}

FSSCM2: »Organisational structure and designed to the purpose of the promotion of cooperation and coordination of activities«

Importance of IT

FSSCM3:«Information technology«

Knowledge sharing

FSSCM 4: »Readiness to share the knowledge «

Trust and openness

FSCM5: »Trust and openness amongst members of the supply chain«

\section{Determinants of SCM}

\section{Global competitiveness}

DSCM1: "Global competitiveness against our supply chain"

\section{Customer needs}

DSCM2: "End customer needs"

DSCM6: "Understanding the on-going trends in market" Integration process

DSCM3: "Integration of processes within supply chain"

DSCM7: "Improving processes and productivity" Cooperation

DSCM4: "Members of supply chain cooperation"

DSCM5: "Internal cross-functional cooperation"

\section{Cost reduction}

DSCM8: "reduction of cost"

\section{Practices of SCM:}

In line internal strategy with Supply chain strategy:

PSCM1: »Members of our supply chain have aligned their product strategies to supply chain strategy«

PSCM5: »Members of our supply chain have aligned their supply strategies to supply chain strategy«

PSCM7: »Members of our supply chain have aligned their distribution strategies to supply chain strategy«

\section{Sustainability}

PSCM2: »Members of our supply chain use sustainability concepts in the supply chain strategy«

PSCM6: »Members of our supply chain promote sustainable operations« Coordination and communication

PSCM3: »Members of our supply chain jointly manage inventory and logistics «

PSCM8: »Members of our supply chain use information technologies to increase the efficiency of communication «

PSCM9: »Members of our supply chain formally exchange production information on a regular basis, eg. through sales and operations planning meetings«

Standardized guidelines

PSCM4: »Members of our supply chain have a standardized quality policy for both products and processes with established guidelines «

PSCM10: »Members of our supply chain have the clear policy related to Supply Chain Management«

\section{Strategic supply chain management}

Inter-organisational communication

SSCM1: »Our organisation has continuous inter-organisational communication for quality improvement program« Cross-organisational team

SSCM2: „Organisation's production process modules can be rearranged so that customization can be carried out latter at distribution centers through cross-organisational team«

High-quality suppliers

SSCM3: »Our organisation strategic planning relies on few high-quality suppliers« Long-term orientation 
SSCM4: »Organisation shares a sense of fair play with its customers to have long-term orientation« SSCM5: „Our organisation's trading partners keep us fully informed about issues that affect its business as part of long-term orientation«

\section{Environmental Sustainability:} Environmental-friendly

ES1: "Environmentally friendly production processes" Waste reduction

ES2: "Acting towards reduction the amount of waste" Reduction of negative impact

ES3: "Engaging in production processes free from harmful substances emissions"

ES5: "Use of renewable sources in production" Creating environmental awareness

ES4: "Involving workers in environment protection schemes"

ES6: "Choosing partners in the supply chain on the basis of environmental guidelines"

\section{Social Sustainability:} Ethical Standards

SS1: "Applying ethical business and trade standards"

SS6: "Applying the code of ethical conduct to employees and contractors" Community related operations

SS2: "Applying fair employment practices to the local community"

SS5: "Contribution in local community charitable donations" Safety standards

SS3: "Providing health and safety equipment" Poverty reduction

SS4: "Investments in poverty reduction programs" 